\title{
Post Hepatitis C Cirrhosis in Sub-Sahara Kidney Transplant, Treated with Sofosbuvir/Ledipasvir: Report of Case and Review of Literature
}

\author{
Tsevi Yawovi Mawufemo1,2*, Lagou Amélie Delphine², Tia Weu Mélanie², \\ Coulibaly Pessa Nawo Albert ${ }^{2}$, Cherif Ibrahima², Guei Monlet Cyr², \\ Ackoundou-N'Guessan Kan Clément ${ }^{2}$
}

\footnotetext{
${ }^{1}$ Nephrology and Dialysis Department of Teaching Hospital Sylvanus Olympio, University of Lomé, Lomé, Togo ${ }^{2}$ Néphrology, Hémodialysis and Organ Transplant Departement of Yopougon Teaching Hospital, University Felix Houphouet Boigny, Abidjan, Cote d'Ivoire

Email: *seviclaude@gmail.com
}

How to cite this paper: Mawufemo, T.Y., Delphine, L.A., Mélanie, T.W., Albert, C.P.N., Ibrahima, C., Cyr, G.M. and Clément, A.-N.K. (2017) Post Hepatitis C Cirrhosis in Sub-Sahara Kidney Transplant, Treated with Sofosbuvir/Ledipasvir: Report of Case and Review of Literature. Open Journal of Nephrology, 7, 95-100.

https://doi.org/10.4236/ojneph.2017.74011

Received: November 11, 2017

Accepted: December 19, 2017

Published: December 22, 2017

Copyright $\odot 2017$ by authors and Scientific Research Publishing Inc. This work is licensed under the Creative Commons Attribution International License (CC BY 4.0).

http://creativecommons.org/licenses/by/4.0/

\section{c) (i) Open Access}

\begin{abstract}
Background: Viral hepatitis $C$ is a major public health problem in the world. The advent of direct-acting antivirals has revolutionized the taking in charge and prognosis of patients infected with the hepatitis $\mathrm{C}$ virus. The interest of this presentation is to draw attention to the problem of therapeutic care posed by viral hepatitis $\mathrm{C}$ in kidney transplant patients in Côte d'Ivoire, a country with limited resources where all direct-acting antivirals are not yet available. Patient observation: We report the case of a kidney transplant of 52 years old, chronic bearer of viral hepatitis $\mathrm{C}$ virus who after his kidney transplant presented, decompensated active cirrhosis. A treatment based on Sofosbuvir $400 \mathrm{mg} /$ Ledipasvir $90 \mathrm{mg}$ in this patient with genotype 2 for 12 weeks was initiated. A sustained virological response was observed 12 weeks after the end of treatment. Conclusion: Direct-acting antivirals offer the possibility of antiviral $\mathrm{C}$ treatment without interferon or ribavirin in cirrhotic renal transplant.
\end{abstract}

\section{Keywords}

Côte D'Ivoire, Direct-Acting Antivirals, Kidney Transplantation, Viral Hepatitis C

\section{Introduction}

Hepatitis C virus (HCV) infection affects more than 200 million people world- 
wide and its prevalence is high in patients with end-stage renal disease thus increasing challenges in renal transplant patients infected with HCV. In developed countries around $1.8 \%$ to $8 \%$ of renal transplant patients are infected with HCV [1]. Despite recent therapeutic advances, the treatment of HCV infection remains a challenge. The arrival of new direct-acting antivirals (DAAs) is a revolution for the treatment of HCV infection and particularly in kidney transplant [2]. In Côte d'Ivoire, a country with limited resources, only a few therapeutic classes of DAAs are available. We report the case of a kidney transplant patient, chronic HCV bearer who presented after his kidney transplant, an array of decompensated cirrhosis in a context of deterioration in general condition and high viral load. The provision of Sofosbuvir/Ledipasvir in Côte d'Ivoire has made it possible to initiate treatment in this patient. All information gathered in this study was processed in accordance with the Code of Ethics. The patient has given his consent regarding this case report.

\section{Patient and Observation}

A 52-year-old married man residing in Abidjan was hospitalized for general impairment in December 2014. Previously, he has had a kidney transplant since June 2008 from a living donor in New Delhi, India. We do not have a record of his hospitalization for the kidney transplant. His immunosuppressive therapy included Tacrolimus, Mycophenolate Mofetil and steroids. His basic creatinine was between $12-14 \mathrm{mg} / \mathrm{l}$. He developed post-transplant diabetes treated with insulin since 2013 . The glycated hemoglobin was $13.6 \%$. There were no complications related to diabetes. He had viral hepatitis $\mathrm{C}$ since the beginning of hemodialysis. He had never received treatment for viral hepatitis C. We do not have information on viral load before kidney transplant, nor on the evaluation of liver fibrosis at the time of hemodialysis. In the history of the disease, he was hospitalized for an alteration of the general condition, digestive disorders (diarrhea made of pasty stools) and impaired renal function. On physical examination, the patient weighed $62 \mathrm{~kg}$ for a height of $173 \mathrm{~cm}$, a body mass index of 20.7 $\mathrm{kg} / \mathrm{m}^{2}$; the temperature was at $37^{\circ} \mathrm{C}$ and the blood pressure measured at $140 / 90$ $\mathrm{mmHg}$. The patient was asthenic. There was jaundice, ascites of moderate abundance and discreet edema of the lower limbs. There was no hepatic encephalopathy, hepatomegaly, or splenomegaly. He had benefited from symptomatic treatment that had improved his clinical condition with persisting impaired renal function. At a complete blood count, there were a normochromic normocytic anemia with a hemoglobin rate at $10.2 \mathrm{~g} / \mathrm{dl}$, white blood cells to $4100 / \mathrm{mm}^{3}$, platelets at $92,000 / \mathrm{mm}^{3}$. ALT was $69 \mathrm{IU} / \mathrm{L}$, AST at $196 \mathrm{IU} / \mathrm{l}$, total bilirubin 25.8 $\mathrm{mg} / \mathrm{l}$, uremia at $0.38 \mathrm{~g} / \mathrm{l}$, creatinine $13.7 \mathrm{mg} / \mathrm{l}$, the rate of prothrombin at $42 \%$. Proteinuria of 24 hours was $0.03 \mathrm{~g} / 24 \mathrm{~h}$. The total proteins were measured at 95 $\mathrm{g} / \mathrm{l}$; albuminemia at $25.3 \mathrm{~g} / \mathrm{l}$, gamma globulins at $17.5 \mathrm{~g} / \mathrm{l}$ with the presence of a beta-gamma block. The inflammater was at 0.82 (A2-A3 activity), the fibro meter at 0.99 , and the cirrhometer at 0.97 (F4 fibrosis). Quantitative HCV-RNA 
was at 5,242,045 UI/ml (6.72 log). The patient had a genotype HCV 2a/2c. Alpha fetoprotein was normal $(6.39 \mathrm{ng} / \mathrm{ml})$. Retroviral Human Immunodeficiency Virus (HIV) serology was negative. Abdominal ultrasound had found a liver cirrhosis, a para-umbilical right kidney transplant and left kidney failure Stage 3. The liver stiffness by Fibroscan was $61.5 \mathrm{kPa}$, IQR/med $14 \%$ and $100 \%$ success rate. The upper gastrointestinal endoscopy had not shown endoscopic signs of portal hypertension. The liver biopsy puncture was not done. The diagnosis of active decompensated viral cirrhosis $C$ in oedemato-ascitic mode was retained with a Child Plugh Turcott B9 score (Ascites: 1; Hepatic encephalopathy: 1; prothrombin: 2; Albumin: 3; Bilirubin: 2). The patient was treated with sofosbuvir $400 \mathrm{mg} /$ lisispavir $90 \mathrm{mg}$ ( 1 tablet daily) for 12 weeks. Tolerance to anti-HCV therapy was excellent and no side effects were observed. Evolution under treatment of biological, biochemical and virological parameters is shown in Table 1 . The patient received treatment based on Sofosbuvir $400 \mathrm{mg} /$ Ledipasvir $90 \mathrm{mg}$ (1 tablet daily) for 12 weeks.

Two years after the end of the treatment, the patient presents a good general condition; the viral load of HCV is always negative (HCV RNA $<15 \mathrm{UI} / \mathrm{ML}$ ), the liver tests are normal (AST at $42 \mathrm{UI} / \mathrm{L}, \mathrm{ALT}$ at $40 \mathrm{UI} / \mathrm{L}$ Rate of prothrombin at $72 \%$.

\section{Discussion}

\subsection{Epidemiology}

Chronic infection with HVC is the most common cause of liver diseases after

Table 1. Evolution under treatment of clinical and biological parameters.

\begin{tabular}{|c|c|c|c|c|c|}
\hline Parameters & Week 0 & Week 4 & Week 8 & Week 12 & $\mathrm{SVR}^{*} 12$ \\
\hline \multicolumn{6}{|l|}{ General condition } \\
\hline asthenia & Yes & Yes & No & No & No \\
\hline nausea & Yes & No & No & No & No \\
\hline ascite & Yes & Yes & No & No & No \\
\hline headache & No & No & No & No & No \\
\hline HCV RNA (UI/ml) & $5,242,045$ & $<15$ & $<15$ & $<15$ & $<15$ \\
\hline HCV RNA (Log) & 6.72 & $<1.2$ & $<1.2$ & $<1.2$ & $<1.2$ \\
\hline Platelets $\left(/ \mathrm{mm}^{3}\right)$ & 92,000 & 80,000 & 82,000 & 96,000 & 120,000 \\
\hline White Blood Cell $\left(/ \mathrm{mm}^{3}\right)$ & 4100 & 5000 & 48,000 & 4800 & 4400 \\
\hline Neutrophil $\left(/ \mathrm{mm}^{3}\right)$ & 767 & 2575 & 1709 & 1800 & 1399 \\
\hline Hemoglobin (g/dl) & 10.2 & 10.9 & 9.5 & 10.2 & 11 \\
\hline AST (UI/l) & 196 & 46 & 43 & 44 & 45 \\
\hline ALT (UI/l) & 69 & 28 & 29 & 28 & 44 \\
\hline Creatinin (mg/l) & 13.7 & 15.6 & 14 & 13.9 & 15.6 \\
\hline Rate of prothrombin (\%) & 42 & 67 & 53 & 54 & 70 \\
\hline
\end{tabular}

${ }^{\star}$ Sustained virologic response 12 weeks off therapy. 
kidney transplantation [3]. The main risk factors for HCV infection in kidney transplant recipient are: dialysis duration and dialysis mode; this is the case of our patient who had contracted HCV probably at his extra-renal cleansing. The risk is higher in hemodialysis than peritoneal dialysis and center hemodialysis than that of home hemodialysis [3].

\subsection{HCV Viral Load and Liver Fibrosis}

We do not have values of HCV viral load and information on liver fibrosis before kidney transplant, but probably he would have had relatively lower hepatic fibrosis and viral load for transplant, compared to viral load and fibrosis after kidney transplant. In the literature, it has been shown a significant increase in HCV viremia a year after the introduction of immunosuppressive treatment with Mycophenolate mofetil [4]. Corticosteroids are also responsible for an increase in viral replication and more rapid progression to cirrhosis in immunocompetent subject [5]. After kidney transplant, there is a rise in serum concentration of HCV RNA which is probably due to the decrease of the immune response under immunosuppressive therapy, and for the establishment of a new balance between the production of virions and their clearance [3] [6] [7] [8].

\subsection{Influence of HCV on the Renal Graft Survival}

In our case, we observed normal kidney function and an absence of proteinuria six years after kidney transplant. Hestin et al. [9] showed that the presence of anti-HCV antibodies before kidney transplantation was predictive of the appearance of proteinuria after transplantation and graft survival of patients infected with HCV and proteinuric is less than that of non-proteinuria patients. Cosio et al. [10] reported that HCV-infected kidney transplants have a high prevalence of acute or chronic vascular rejection in the first six months after transplantation, resulting in decreased graft survival. Conversely, other authors have reported a lower rate of acute rejection in kidney transplant patients with HCV compared to kidney transplant patients not infected with HCV [11]. This reduction in graft survival seems to be due to the appearance of glomerular diseases attributable to the virus [11]. Recently, it has been shown that in HCV + kidney transplant patients with de novo glomerular diseases, the occurrence of these glomerular was not related to either an increase in the serum HCV RNA concentration after transplantation, nor to an effect describes the virus on kidney cells, but rather to a change in the immune response [7].

\subsection{Combination Sofosbuvir/Ledipasvir and HCV Genotype 2}

There are no major studies evaluating the combination Sofosbuvir/Ledipasvir in HCV infected patients with HCV genotype 2 and Ledipasvir has a low activity on HCV genotype [12]. The combination Sofosbuvir/Ledipasvir was approved by the European Association for the Study of Liver (EASL) for the treatment of HCV genotype 1, 4, 5, and 6 [13]. Therapeutic options for treating patients in- 
fected with HCV genotype 2 are based on the combination Sofosbuvir/Ribavirin or Sofosbuvir/Daclatasvir [13]. Given the recognized side effects of ribavirin such as anemia [14] and the unavailability of DAAs such as Daclatasvir in Côte d'Ivoire at the time of treatment of our patient, the only treatment option based on DAAs without interferon or ribavirin in this infected HCV kidney transplant recipient genotype 2 was Sofosbuvir/Ledipasvir; which justified its use in our patient. The rapid virological response was observed at initiation of treatment as well as the sustained virological response at 12 weeks after the end of treatment. We did not find in the literature a study evaluating the combination sofosbuvir/ledipasvir in kidney transplant patients infected with HCV genotype 2. However a rapid virologic response was observed in 22 of 25 patients (88\%) in the series Kamar et al. [15]; they also found that at the end of treatment, HCV RNA was undetectable in all patients. 4 to 12 weeks after therapy with DAAs, all patients had a sustained virologic response and normalization of transaminases. Tolerance to anti-HCV therapy was excellent and no adverse effects were observed. They therefore concluded that the DAAs are effective and safe for treating HCV infection after kidney transplantation.

\section{Conclusion}

Hepatitis C in the kidney transplant is common. Here we report the efficacy of the Sofosbuvir/Ledipasvir combination in a genotype 2 positive HCV patient. This is the first case diagnosed in black francophone Africa. The evolution was favorable with a sustained viral response 12 weeks after the end of treatment. The hope of accessible treatment and affordable is therefore possible in black Africa for HCV positive hemodialysis patients as well as HCV positive kidney transplant patients.

\section{References}

[1] Scott, D.R., Wong, J.K., Spicer, T.S., Dent, H., Mensah, F.K., et al. (2010) Adverse Impact of Hepatitis C Virus Infection on Renal Replacement Therapy and Renal Transplant Patients in Australia and New Zealand. Transplantation, 90, 1165-1171. https://doi.org/10.1097/TP.0b013e3181f92548

[2] Baid-Agrawal, S., et al. (2014) Hepatitis C Virus Infection and Kidney Transplantation in 2014: What's New? American Journal of Transplantation, 14, 2206-2220. https://doi.org/10.1111/ajt.12835

[3] Morales, J.M. and Campistol, J.M. (2000) Transplantation in the Patient with Hepatitis C. Journal of the American Society of Nephrology, 11, 1343-1353.

[4] Rostaing, L., Izopet, J., Sandres, K., Cisterne, J.M., Puel, J. and Durand, D. (2000) Changes in Hepatitis C Virus RNA Viremia Concentrations in Long-Term Renal Transplant Patients after Introduction of Mycophenolate Mofetil. Transplantation, 69, 991-994. https://doi.org/10.1097/00007890-200003150-00055

[5] Magrin, S., Craxi, A., Fabiano, C., et al. (1994) Hepatitis C Viremia in Chronic Liver Disease: Relationship to Interferon-Alfa or Corticosteroid Treatment. Hepatology, 19, 273-279. https://doi.org/10.1002/hep.1840190203

[6] Izopet, J., Rostaing, L., Sandres, K., et al. (2000) Longitudinal Analysis of Hepatitis 
C Virus Replication and Liver Fibrosis Progression in Renal Transplant Recipients. The Journal of Infectious Diseases, 181, 852-858. https://doi.org/10.1086/315355

[7] Kamar, N., Rostaing, L., Boulestin, A., et al. (2003) Evolution of Hepatitis C Virus Quasispecies in Renal Tranplant Patients with De Novo Glomerolonephritis. Journal of Medical Virology, 69, 482-488. https://doi.org/10.1002/jmv.10335

[8] Alric, L. Di-Martino, V., Selves, J., Cacoub, P., et al. (2002) Long-Term Impact of Renal Transplantation on Liver Fibrosis during Hepatitis C Virus Infection. Gastroenterology, 123, 1494-1499. https://doi.org/10.1053/gast.2002.36610

[9] Hestin, D., Guillemin, F., Castin, N., Le Faou, A., Champigneulles, J. and Kessler, M. (1998) Pretransplant Hepatitis C Virus Infection: A Predicator of Proteinuria after Renal Transplantation. Transplantation, 65, 741-744. https://doi.org/10.1097/00007890-199803150-00024

[10] Cosio, F.G., Sedmak, D.D., Henry, M.L., et al. (1996) The High Prevalence of Severe Early Post-Transplant Renal Allograft Pathology in Hepatitis C Positive Recipients. Transplantation, 62, 1054-1059. https://doi.org/10.1097/00007890-199610270-00004

[11] Pascual, J., Crespo, M., Mateos, M.L., et al. (1998) Reduced Severity of Acute Rejection in Hepatitis C Virus Positive Renal Allograft Recipients: Are Milder Immunosuppressive Regimens Advisable? Transplantation Proceedings, 30, 1329-1330. https://doi.org/10.1016/S0041-1345(98)00263-2

[12] Nkuize, M., Sersté, T., Buset, M. and Mulkay, J.P. (2016) Combination Ledipasvir-Sofosbuvir for the Treatment of Chronic Hepatitis C Virus Infection: A Review and Clinical Perspective. Therapeutics and Clinical Risk Management, 12, 861-872. https://doi.org/10.2147/TCRM.S77788

[13] European Association for the Study of the Liver (2015) EASL Recommendations on Treatment of Hepatitis C 2015. Journal of Hepatology, 63, 199-236. https://doi.org/10.1016/j.jhep.2015.03.025

[14] Garnier, J.L., Chevallier, P., Dubernard, J.M., Trepo, C., Touraine, J.L. and Chossegros, P. (1997) Treatment of Hepatitis C Virus Infection with Ribavirin in Kidney Transplant Patients. Transplantation Proceedings, 29, 783. https://doi.org/10.1016/S0041-1345(96)00100-5

[15] Kamar, N., Marion, O., Rostaing, L., et al. (2016) Efficacy and Safety of Sofosbuvir-Based Antiviral Therapy to Treat Hepatitis C Virus Infection after Kidney Transplantation. American Journal of Transplantation, 16, 1474-1479. https://doi.org/10.1111/ajt.13518 